\title{
“Coated diamonds": formed more often than we meet?
}

\author{
S. S. Lobanov (1,2), V. P. Afanasiev (1), N. P. Pokhilenko (1), V.G.Vins (2) \\ (1) Institute of Geology and Mineralogy, Siberian Branch of Russian Academy of Sciences, \\ Novosibirsk,630090, Russia (geoggf@ngs.ru / Phone: +7-961-215-7933) \\ (2) New Diamonds of Siberia Ltd., Russkya st. 43, Novosibirsk, Russia (nbs-nsk@mail.ru /
}

Fax: +7(383)363-0281 / Phone: +7(383)363-0281)

\section{Introduction}

Coated diamonds are widespread. They typically have a zonal structure: usually a clear and colorless core and a heavily included coloreless, grayish or yellowish coat. Such diamonds are common for some kimberlites of Yakutia and also for kimberlites and alluvial deposits of other regions. For the Snap Lake/King Lake diamonds Yelisseyev et al. (2004) showed that the majority of them (possibly all) originally had coats, but the coats were partly or fully dissolved in the kimberlitic melt. To check this hypothesis, coated diamonds from Snap Lake (Canada) were studied.

\section{Experiment}

Only 4 coated diamonds were found/chosen out of several dozens of examined diamonds. These diamonds were polished along $\{100\}$ or $\{110\}$ planes and etched in the $\mathrm{NaNO}_{3}$ melt in air at a temperature range of 550$650{ }^{0} \mathrm{C}$. The etching degree was measured by means of an optical and SEM microscope. Also, cathodoluminescence (CL) images were made in order to study the natural zonal structure of these diamonds.

\section{Morphology and features of coated diamonds}

The studied diamonds were characterized by various internal and external morphology. The presence of one or several growth zones which were clearly seen on the CL-image was typical of their structure (Fig. 1).

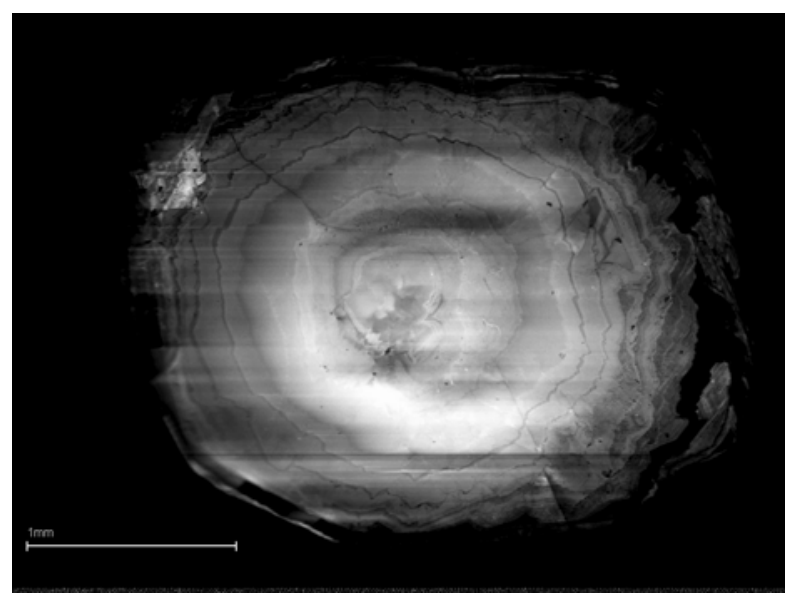

Fig. 1 Sample SL-14 before the etching. CL-image. Zonal structure.
In addition, the CL-images showed that the outer zones often „cut“ earlier zones making their contact irregular and non-conform. This fact is due to the partial dissolution of the diamonds (sometimes repeated) at some stages of their growth histories. The coats of some crystals were partially dissolved in the kimberlitic magma, as it was seen in sample SL-14 (Fig. 2).

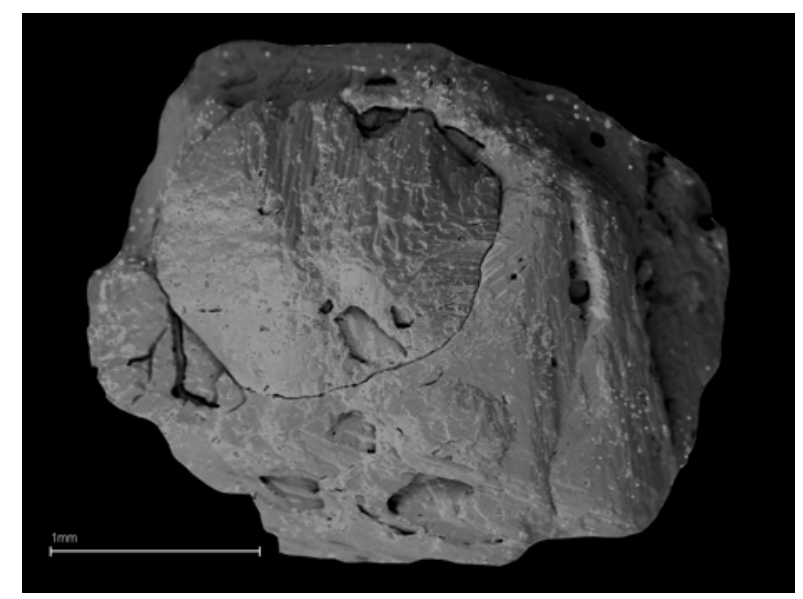

Fig. 2 Sample SL-14. Coated diamond before the etching. The cracks between the core and the rim of the crystal can be observed. Most likely they formed during the dissolution in the kimberlitic magma.

It is important that the core remained almost unaffected by the etching, while deep cracks began to etch between the core and the coat.

\section{Experimental Results}

First signs of etching were noted at $550{ }^{0} \mathrm{C}$ after one hour exposition. Scratches caused by the polishing machine appeared on the polished surfaces of the diamonds, but the structural defects were not observed. The etching at $650{ }^{\circ} \mathrm{C}$ for 3 hrs showed no considerable changes either in the coats, or in the cores, but some specific signs of oxidation appeared (Fig. 3). The combination of cathodoluminescence and microrelief images of the same polished surface shows how the octahedral growth layers are „cut” by the dissolution zone, which is overgrown by the coat later. It should be mentioned that the coat shows no (or very weak) cathodoluminescence (Fig. 3-I). It is in agreement with the results obtained by Yelisseyev et al. (2004), hwo showed that, this is due to numerous silicate submicron 
inclusions and/or A-defects which predominate, and quench the CL. Along the core-coat boundary the system of etch pits forms (Fig. 3-II, 3-I+II).

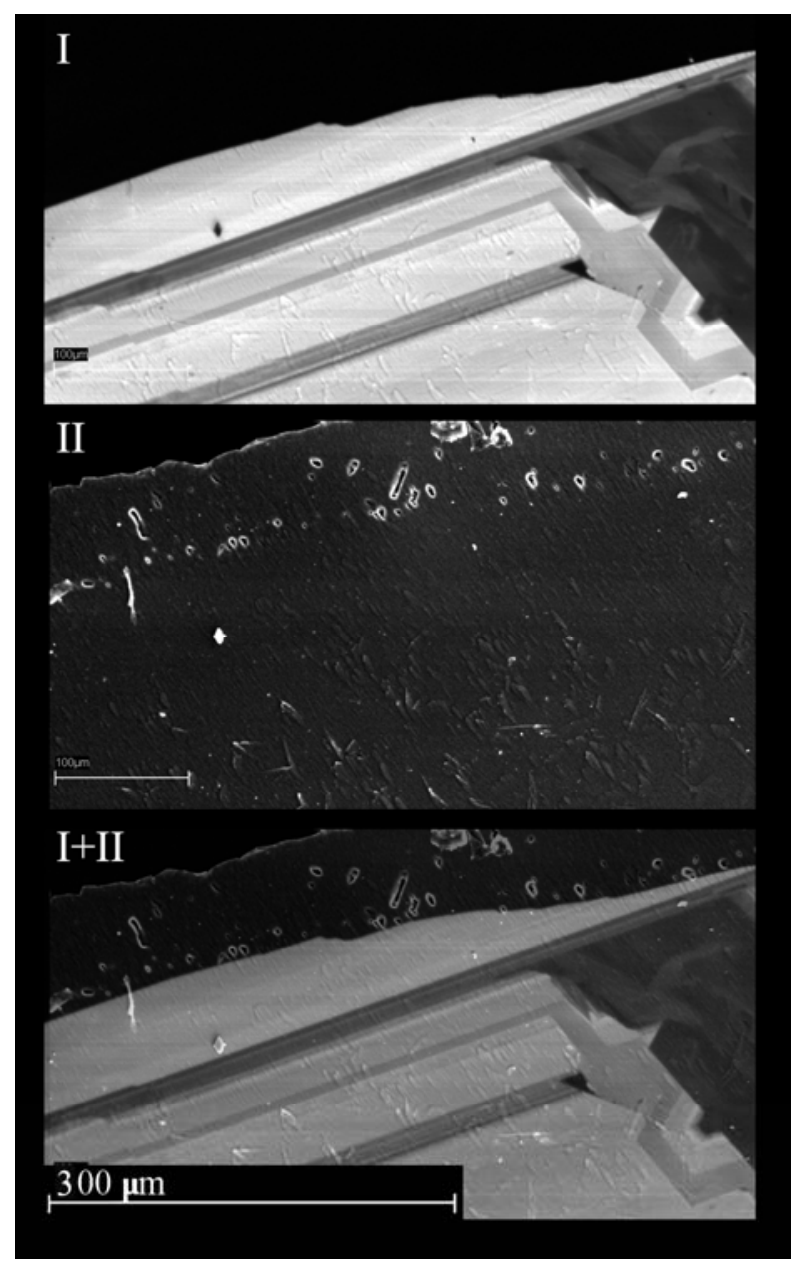

Fig. 3 Fragment of sample SL-11 after etching. I - CLimage, showing octahedral growth layers, which are „cut” by the dissolution zone. II - microrelief of the same fragment, the photo was made using secondary electrons. I+II - pictures I and II combined, note that the rim shows no CL.

Different structural defects of the crystals is the reason of their different etching behaviour. The boundary between the core and rim is the most vulnerable place at $650{ }^{\circ} \mathrm{C}$, and rather deep cracks are found between them (Fig. 4). This corresponds to the cracks between the core and the coat seen in natural etched diamonds (Fig. 2)

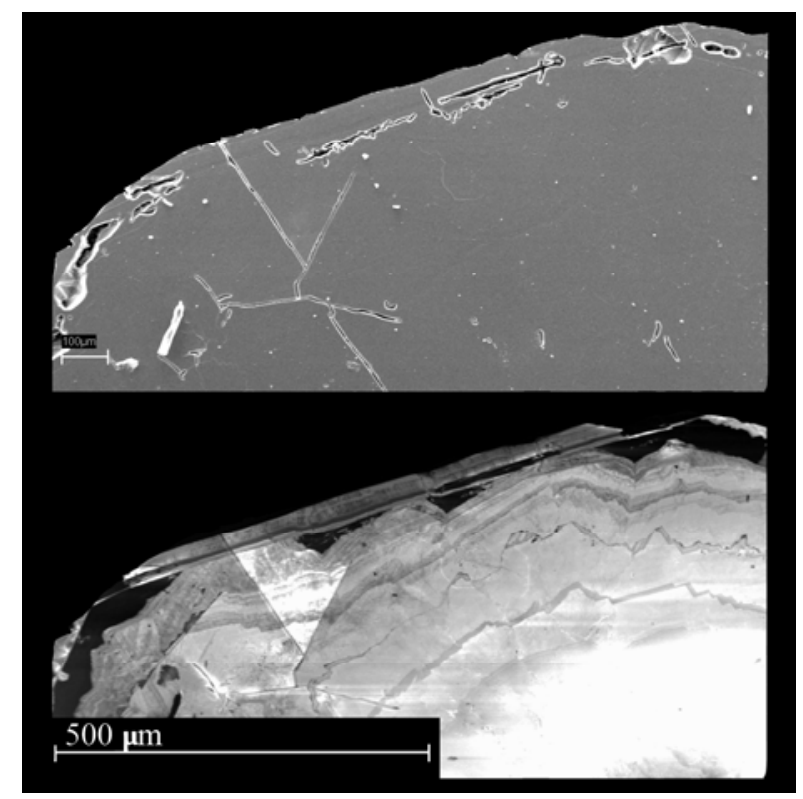

Fig. 4 Fragment of sample SL-14 after etching. On top is a secondary electron photo with clear etch cracks along the crystal borders, below is a CL-image. One can see that extended etching channels correspond to the zonal structure of the diamond and are located on the core-coat border.

The study of the Snap Lake diamonds showed that coated diamonds could have been more widespread in kimberlites, but their coats were destroyed by the kimberlitic melt.

Coats grow much later than the core of the diamonds and they seem to be the final stage of diamond crystallization.

In general, it could be accepted that the lowest temperature at which etching of the coat would take place in the $\mathrm{NaNO}_{3}$ melt, while the core would still be intact, could be about $650{ }^{\circ} \mathrm{C}$ and higher.

\section{References}

Yelisseyev A.P., Pokhilenko N.P., Steeds J.W., et al., 2004. Features of coated diamonds from Snap Lake/King Lake kimberlite dyke, Slave craton, Canada, as revealed by optical topography. Lithos 77 (2004) 83-98. 